\title{
Negative pressure pulmonary edema: endobronchial intubation or acute lung injury in a predisposed patient?
}

\author{
Rakesh Garg
}

Received: 3 November 2008/Revised: 17 November 2008/Accepted: 15 December 2008/Published online: 31 January 2009

(c) Canadian Anesthesiologists' Society 2009

\section{To the Editor,}

I read with interest the case of unilateral negative pressure pulmonary edema (NPPE) due to endobronchial intubation. ${ }^{1}$ While the possibility of NPPE cannot be excluded, the details of the case suggest that other possible factors may have contributed to the clinical findings. One such factor that should also be considered is acute lung injury subsequent to hypoxemia and trauma, caused by repeated use of suction on the endotracheal tubes and possibly related to pulmonary hypertension from untreated obstructive sleep apnea.

Repeated use of suction on the endotracheal tubes has been reported to induce lung injury and NPPE. ${ }^{2}$ The authors described the hazards of repeated use of suction, including vacuuming of respiratory gases, secretion of fluids that may lead to the collapse of alveoli, subsequent loss of lung volume, and hypoxemia. Large suction catheters can generate sub-atmospheric pressures and may elicit extravasation of fluid into the alveoli. ${ }^{3}$ Pulmonary hemorrhage has also been associated with paroxysmal coughing, which also occurred in this patient. ${ }^{4}$ The copious secretions at the end of surgery could have been attributed to a light plane of anesthesia or repeated use of suction. As the patient had a history of respiratory infections, this may have rendered the conducting airways more susceptible to the trauma of repeatedly applying suction.

In light of these considerations, the differential diagnosis of unilateral pulmonary edema can be rather extensive and multifactorial.

Conflicts of interest None declared.

\section{References}

1. Goodman BT, Richardson MG. Case report: Unilateral negative pressure pulmonary edema-a complication of endobronchial intubation. Can J Anesth 2008; 55: 691-5.

2. Pang WW, Chang DP, Lin CH, Huang MH. Negative pressure pulmonary oedema induced by direct suctioning of endotracheal tube adapter. Can J Anaesth 1998; 45: 785-8.

3. Schwartz DR, Maroo A, Malhotra A, Kesselman H. Negative pressure pulmonary hemorrhage. Chest 1999; 115: 1194-7.

4. Dolinski SY, MacGregor DA, Scuderi PE. Pulmonary hemorrhage associated with negative pressure pulmonary edema. Anesthesiology 2000; 93: 888-90.

R. Garg ( ()

All India Institute of Medical Sciences, New Delhi, India

e-mail: drrgarg@hotmail.com 